\title{
Nepenthes cabanae (Caryophyllales, Nepenthaceae), a new species of pitcher plant from Central Mindanao, Philippines
}

\author{
Noel E. Lagunday ${ }^{1 *}$ And Victor B. Amoroso ${ }^{1,2}$
}

\begin{abstract}
A new endemic species, Nepenthes cabanae, belonging to sect. Insignes is described from the Mt. Pantaron range of central Mindanao. The species is assessed as Critically Endangered. This discovery brings the number of Nepenthes species in this mountain range to eight. Mt. Pantaron is currently not a protected area, but the diversity of Nepenthes taxa suggests concerted efforts should be made to develop a conservation strategy to preserve and protect the area.
\end{abstract}

Keywords: carnivorous plants, Nepenthes, Pantaron range, taxonomy, threatened species

\section{Introduction}

Nepenthes species in the Philippines can be assigned to four main groups: section Alatae Cheek \& Jebb (2016b), section Insignes Danser (1928), section Micramphorae Cheek \& Jebb (2013e) and section Villosae Cheek \& Jebb (2016b). Other sections in Malesia include Regiae Danser (1928) from Borneo, Sulawesi and New Guinea, section Nobiles Danser (1928) restricted to Borneo (Cheek \& Jebb 2001) and section Tentaculatae Cheek \& Jebb (2016a) from Sulawesi while some species do not fit into any of these groups and have isolated positions (Cheek \& Jebb 2013f).

Surveys of previously under-explored areas in the Philippines by Nepenthes enthusiasts (e.g., Heinrich et al. 2009, Gronemeyer et al. 2014, Gronemeyer et al. 2016, Amoroso et al. 2017, Lagunday et al. 2017) and discoveries of overlooked new species among herbarium specimens (Cheek 2011; Cheek \& Jebb 2013a, b, c, d \& e; Cheek \& Jebb 2014) have increased the number of species known from 12 (Cheek \& Jebb 2001) to 57 species (Pelser et al. 2011 onwards). Mindanao is home to 34 species of Nepenthes (Pelser et al. 2011 onwards) and has the highest diversity of the genus followed by Palawan (Cheek \& Jebb 2013e). Sohmer \& Davis (2007) estimated that species

${ }^{1}$ Center for Biodiversity Research and Extension in Mindanao (CEBREM), Central Mindanao University, Musuan, Bukidnon, Philippines

${ }^{2}$ Biology Department, Central Mindanao University, Musuan, Bukidnon, Philippines

*Corresponding email: lagundaynoel@gmail.com

Date Submitted: 21 May 2019

Date Accepted: 11 November 2019 extinction levels in the Philippines because of habitat destruction may be as high as $9-28 \%$ and until habitat destruction is addressed, discovery of new Nepenthes species is a race against time (Cheek \& Jebb 2013e). This calls for conservation initiatives from a range of stakeholders.

Mt. Malimumu, San Fernando, Bukidnon is part of the Pantaron Range, which is not a protected area and botanically under-explored because of tribal animosity and political instability. Previous explorations in the area have discovered two new species of Nepenthes and have documented the Nepenthes species in the area (Lagunday et al. 2017). Recent explorations conducted to botanize the mountain ecosystem led to the discovery of the new species described herein.

\section{Materials and Methods}

\section{Field Sampling and Processing}

Field explorations were conducted from August to September 2015 in Mt. Malimumu, Pantaron range, central Mindanao, Philippines (see Fig. 1). Data were derived from live plants in the field and from the herbarium type. Wet method was applied in the collection and preservation of the specimens, which were deposited in the Central Mindanao University Herbarium (CMUH).

\section{Results and Discussions}

A new species of Nepenthes is here recognized among the collection from the field exploration.

Nepenthes cabanae Lagunday \& V.B. Amoroso, sp. nov. Diagnosis: Leaves unequally decurrent with four longitudinal nerves; lower pitchers subcylindrical, bottom half slightly 


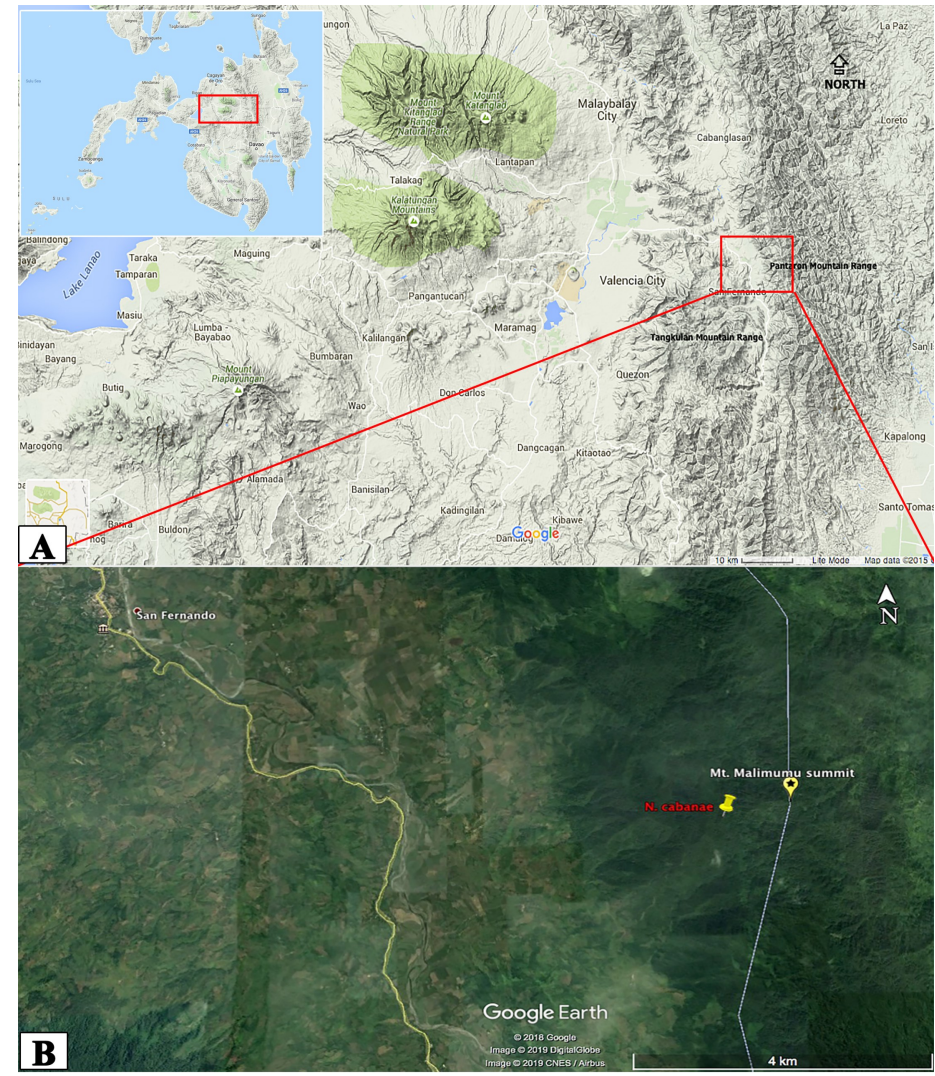

Figure 1. Mt. Malimumu, Pantaron range, Mindanao, Philippines. A) Central Mindanao (inset, Mindanao Island), B) location of type locality of Nepenthes cabanae.

inflated, top half cylindrical towards the mouth; peristome with short triangular indistinct teeth not projecting beyond peristome margin.

Type: Philippines, Mindanao, Pantaron range, Bukidnon, San Fernando, Mt. Malimumu (1,050 masl), 18 August 2015 Lagunday N.E. 0003 (Holotype: 257966 PNH; Isotypes: 00009843 CMUH, 00011174 CMUH).

Description: TERRESTRIAL, scrambling on neighboring plants for support; Climbing STEM to $8 \mathrm{~m}$ long and 6-8 $\mathrm{mm}$ in diameter, sub-angular, internodes $3-4.5 \mathrm{~cm}$, axillary buds inconspicuous; LEAVES $26.3-34 \mathrm{~cm}$ long x 3.2-4.6 cm wide, \pm linear, sessile; unequally decurrent; apex acute; base scarcely tapering; margin irregularly recurved; with 4 longitudinal nerves running parallel with the midrib; pennate nerves at 30 $60^{\circ}$ from the midrib, numerous, moderately conspicuous; midrib reddish-brown and contrasting with green lamina.

LOWER/INTERMEDIATE PITCHER generally subcylindrical, bottom half slightly inflated, top half becoming narrow and cylindrical towards the mouth; $16-18 \mathrm{~cm}$ long, 3-
$4.5 \mathrm{~cm}$ wide (widest point), waxy zone $12-13 \mathrm{~cm}$ long $(67-75 \%$ of the pitcher length), digestive zone $3-4.5 \mathrm{~cm}(25-33 \%$ of the pitcher length); wings running down the pitcher anterior, 5-12 $\mathrm{cm}$ long, diminishing as ridges towards the tendril, ridges 3-4 $\mathrm{mm}$ wide, fringe elements to $4 \mathrm{~mm}$ long; mouth ovate tapering posteriorly forming a distinct slightly anteriorly inclined neck; peristome flattened, $1.5-2.2 \mathrm{~cm}$ wide, ribs to $1 \mathrm{~mm}$ apart, teeth indistinct and not projecting beyond margin, triangular, ca. $0.3-$ $0.5 \mathrm{~mm}$ long, nectar glands proximally sunken in the semilunar depressions between the ribs with canals emptying into the inner pitcher walls; spur filiform, unbranched, $1-1.3 \mathrm{~cm}$ long and to $1 \mathrm{~mm}$ in diameter; indumentum of three types, short stellate brown hairs, long and short bushy brown hairs to ca. $1 \mathrm{~mm}$ long, and long brown erect hairs to ca. $1 \mathrm{~mm}$ long with 2-4 short arms arising from the central axis; lid nearly orbicular $3.4-4.6 \mathrm{~cm}$ long x 2.9-4 cm wide, apex notched, base cordate, lid appendage reduced to a rudimentary keel, nectar glands ovateelliptic ca. $0.2-0.3-$ ca. $0.5 \times 0.7 \mathrm{~mm} \times 0.4-0.5 \mathrm{~mm}$ evenly distributed towards the lid margin; tendrils non-coiling, 26-29 $\mathrm{cm}$ long and to $5 \mathrm{~mm}$ in diameter.

UPPER PITCHER subcylindrical, bottom half slightly inflated, broadly funnel-shaped tapering toward the tendril, top half slightly narrowed forming a hip becoming cylindrical to slightly funnel-shaped towards the mouth; $16-19.5 \mathrm{~cm}$ long and to $5 \mathrm{~cm}$ wide (widest point), waxy zone to $12 \mathrm{~cm}(62-75 \%$ of the pitcher length) digestive zone to $4 \mathrm{~cm}(75-79 \%$ of the pitcher length); wings occasionally present and are as in lower pitchers except that fringe elements to $3 \mathrm{~mm}$ long; mouth ovate, tapering posteriorly to form a distinct vertically/slightly anteriorly inclined neck; peristome flattened $1.1-1.7 \mathrm{~cm}$ wide, ribs ca. $0.5-0.7 \mathrm{~mm}$ apart, teeth and glands, spur, indumentum, lid and glands as in lower pitcher; tendrils coiling, $30-32 \mathrm{~cm}$ long and to $5 \mathrm{~mm}$ in diameter.

Color of living plants is much suffused with red. Peristome of upper pitchers greenish-yellow with narrow bands of maroon red. Pitchers marbled with red flecks towards mouth, tending to greenish at base. Lid marbled red throughout.

The plant habit and gross morphology of Nepenthes cabanae is illustrated in Figure 2-5.

Etymology: The specific epithet honors Dr. Veneracion G. Cabana, who funded scientific expeditions in the unexplored areas in central Mindanao, Philippines viz. Mt. Pantaron range and Mt. Tangkulan range.

\section{Notes on Taxonomy}

Nepenthes cabanae morphologically falls under Nepenthes sect. Insignes Danser (Cheek et al. 2018) being characterized by lack of petiole, broadly subcylindrical pitchers, broad 


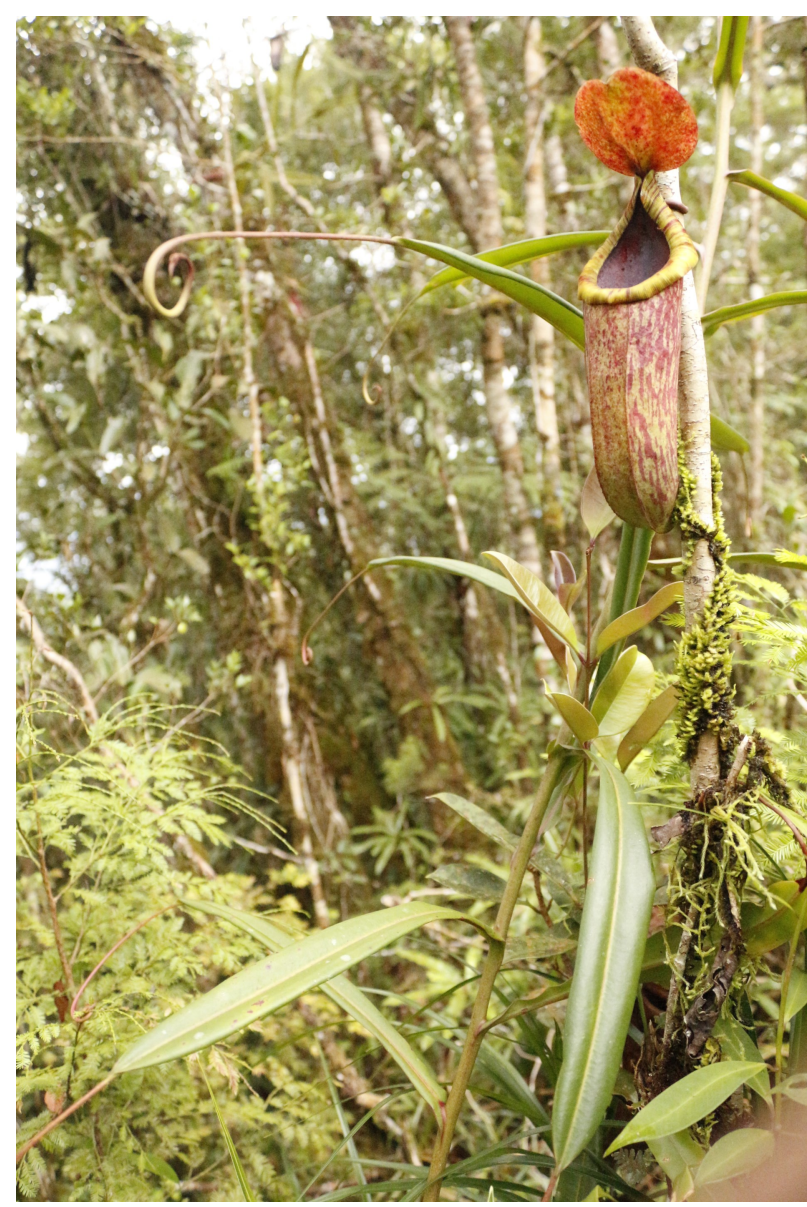

Figure 2. Upper pitchers on living plants of Nepenthes cabanae. (Photo: N.E. Lagunday).

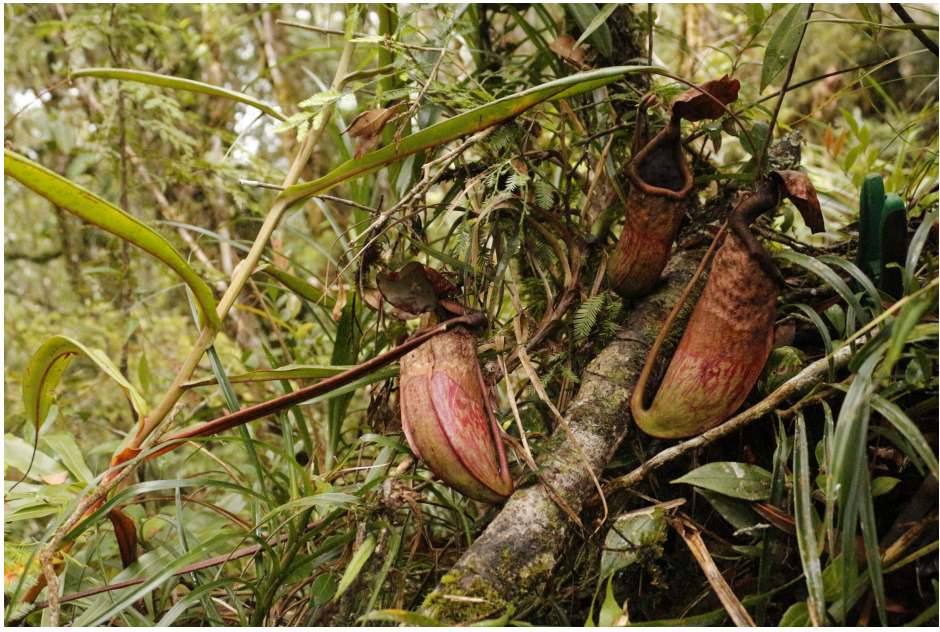

Figure 3. Upper pitchers and leaf attachment on living plant of Nepenthes cabanae. (Photo: N.E. Lagunday).

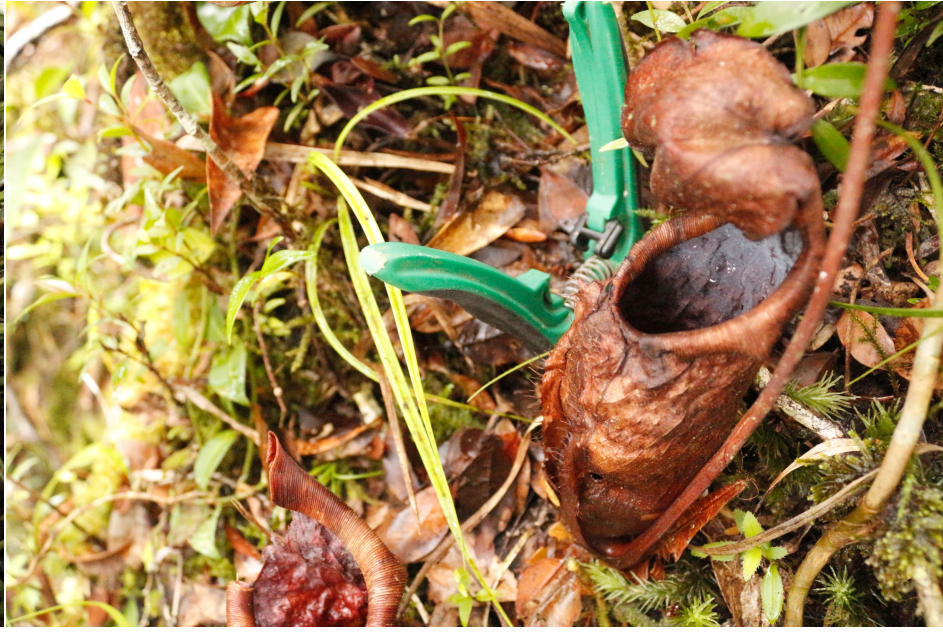

Figure 4. An intermediate pitcher on living plant of Nepenthes cabanae. (Photo: N.E. Lagunday). 


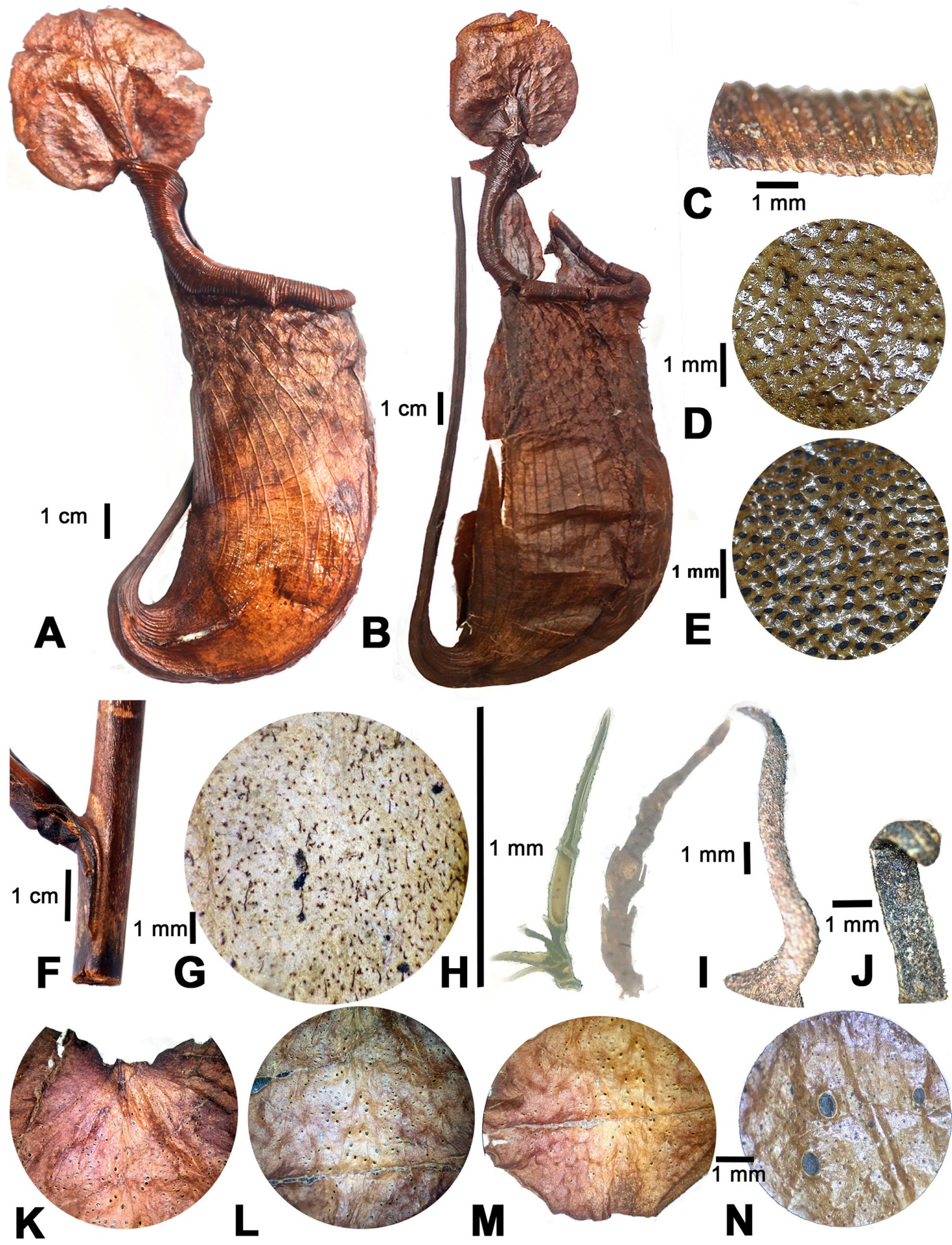

Figure 5. Nepenthes cabanae A) upper pitcher, B) intermediate pitcher, C) peristome inner margin, D) waxy zone, E) digestive zone, F) leaf attachment, G) pitcher exterior with indumentum, H) indumentum types, I \& J) lid spur, $\mathrm{K})$ gland distribution in the basal lower lid surface, L) gland distribution in the mid lower lid surface, M) gland distribution in the apical lower lid surface, N) nectar glands in the lower lid surface. All from the holotype. (Photos: N.E. Lagunday). 
peristomes, lids which lack appendages and transversely elliptic nectar glands. It is closest to N. surigaoensis Elmer, which also belongs in the same section. However, N. surigaoensis has strong equally decurrent leaves, with three to four longitudinal nerves and with lower pitchers wholly cylindrical or ellipsoidal; peristome teeth in N. surigaoensis are distinct and projecting beyond margin unlike those in $N$. cabanae (Table 1). Nepenthes cabanae can also be confused with $N$. manobo Lagunday et al., except that for $N$. cabanae, leaf attachment is unequally decurrent, leaf lamina has four longitudinal nerves and occasionally winged upper pitchers whereas, N. manobo leaf attachment is not-decurrent, only three nerves in the leaf lamina and absent upper pitchers wings.

Morphological data suggests that the species described is not of a hybrid origin as it has stable population and unique characters delineating it from other species observed in the area.

\section{Notes on Distribution and Ecology}

Nepenthes cabanae populations were observed in the montane tropical rain forest, scrambling on understory plants and shrubs with clay substrate and less sunlight exposure. They occur only in Mt. Malimumu, Pantaron range at 1,020-1050 masl and is recorded nowhere else. The name Pantaron derives from "pantad" in the local dialect, meaning gravel, which is dominating the mountain from 500-1,020 masl. The range is mostly covered by montane forest dominated by Agathis philippinensis Warb. (Araucariaceae), Dacrycarpus sp. (Podocarpaceae), Falcatifolium gruezoi de Laub. (Podocarpaceae), Gymnostoma rumphianum (Miq.) L.A.S. Johnson (Casuarinaceae), Lithocarpus spp. (Fagaceae), Phyllocladus hypophylus Hook.f. (Podocarpaceae) and Shorea spp. (Dipterocarpaceae).

A total of eight species of Nepenthes have so far been recorded on Mt. Pantaron range. Nepenthes malimumuensis Lagunday et al. and N. manobo, were recently described from collections in the same mountain (Lagunday et al. 2017). Five other Nepenthes species occurring in the area are $N$. cornuta Marwinski et al., N. pulchra Gronem. et al., N. surigaoensis, $N$. talaandig Gronem. et al., and N. truncata Macfarl. These are often associated with various scrambling ferns and lycopods including Dicranopteris linearis (Burm. f.) Underw. (Gleicheniaceae), Dipteris conjugata Reinw. (Dipteridaceae), Gleichenia hirta Blume (Gleicheniaceae), Lycopodiella cernua (L.) Pic. Serm. (Lycopodiaceae) and Pteridium aquilinum (L.) Kuhn (Dennstaedtiaceae).

Only ca. 10 individuals ca. 10-25 m apart were recorded during sampling, these were observed along ridge trails connecting several Manobo tribe villages along the mountain range. The elevational range of the species is from 1,020-1050 masl and was only observed on Mt. Malimumu, Pantaron range, San Fernando, Bukidnon Province of Mindanao Island. Population count was limited to the individuals observed along the ridge as most of the population were difficult to access because of the terrain.

\section{Conservation Notes}

Nepenthes cabanae is assessed here as Critically Endangered [CR B1ab (i)] (IUCN 2012); with an estimated extent of occurrence of less than $10 \mathrm{~km}^{2}$, it is likely to suffer habitat loss from quarrying, illegal logging, agriculture and slash and burn. The species is known only from the Mt. Pantaron range and is likely to be endemic to the mountain, which faces threats of deforestation and habitat loss.

Table 1. Characters delineating N. cabanae from N. surigaoensis

\begin{tabular}{|c|c|c|}
\hline Characters & $\begin{array}{l}\text { Nepenthes cabanae Lagunday and } \\
\text { V.B. Amoroso sp. nov. }\end{array}$ & N. surigaoensis Elmer \\
\hline Leaf attachment & $\begin{array}{l}\text { Sessile leaves clasping up to half of } \\
\text { the stem running down the internode } \\
\text { unevenly }\end{array}$ & Strongly decurrent \\
\hline $\begin{array}{l}\text { Number of longitudinal nerves } \\
\text { running in parallel with the midvein }\end{array}$ & 4 & $3-4$ \\
\hline Lower /Intermediate pitchers & Subcylindrical & Wholly cylindrical or ellipsoidal \\
\hline Peristome margin & $\begin{array}{l}\text { Short triangular teeth ca. } 0.3-0.5 \mathrm{~mm} \\
\text { long not projecting beyond margin }\end{array}$ & $\begin{array}{l}\text { Distinct teeth ca. } 0.8-1.0 \mathrm{~mm} \text { long, } \\
\text { projecting beyond margin }\end{array}$ \\
\hline
\end{tabular}




\section{Conclusion And Recommendation}

Explorations in the incompletely surveyed areas of central Mindanao, Philippines led to the discovery of $N$. cabanae another new species of pitcher plant making the Philippines home to a total of 58 species. This discovery makes the Mt. Pantaron range a home to eight Nepenthes species. Mt. Pantaron is currently not a protected area, and the presence of threatened and endemic species of Nepenthes in the area calls for immediate conservation strategies by the local stakeholders to preserve and protect these plants from illegal poaching

\section{Acknowledgements}

The authors are grateful to the Department of Environment and Natural Resources (DENR) Region $\mathrm{X}$ for the Gratuitous Permit, Datu Novo Sabas for field sampling assistance, Local Government Units, Indigenous People Mandatory Representative (IPMR) and tribal chieftain of Barangay Magkalungay, San Fernando, Bukidnon for the logistics support.

\section{Literature Cited}

Amoroso, V.B., N.E. Lagunday, F.P. Coritico \& R.D. Colong, 2017. Nepenthes alfredoi (Caryophyllales: Nepenthaceae), a new species of pitcher plant from Mindanao, Philippines. Philippine Journal of Systematic Biology, 11: 14-19.

Cheek, M., 2011. Nepenthes robcantleyi sp. nov. (Nepenthaceae) from Mindanao, Philippines. Nordic Journal of Botany 29: 677-681. http://dx.doi.org/10.1111/ j.1756-1051.2011.01449.x

Cheek, M. \& M. Jebb, 2001. Nepenthaceae. In: Nooteboom H.P. (ed.) Flora Malesiana I. 15, Flora Malesiana Foundation, Nationaal Herbarium Nederland, Leiden. pp. 1161.

Cheek, M. \& M. Jebb, 2013a. Identification and typification of Nepenthes blancoi Blume, with N. abalata sp. nov. from the Western Visayas, Philippines. Nordic Journal of Botany, 31: 151-156. http://dx.doi. org/10.1111/j.17561051.2012.00012.x

Cheek, M. \& M. Jebb, 2013b. Nepenthes alzapan (Nepenthaceae), a new species from Luzon, Philippines. Phytotaxa, 100: 57-60. http://dx.doi.org/10.11646/ phytotaxa.100.1.6

Cheek M. \& M. Jebb, 2013c. Nepenthes ramos (Nepenthaceae), a new species from Mindanao, Philippines. Willdenowia, 43: 107-111. http://dx.doi.org/10.3372/wi.43.43112

Cheek, M. \& M. Jebb, 2013d. Typification and redelimitation of
Nepenthes alata Blanco with notes on the $N$. alata group, and $N$. negros sp. nov. from the Philippines. Nordic Journal of Botany 31: 616-622. http://dx.doi.org/10.1111/j.17561051.2012.00099.x

Cheek, M. \& M. Jebb, 2013e. The Nepenthes micramphora (Nepenthaceae) group, with two new species from Mindanao, Philippines. Phytotaxa 151 (1): 25-34. http:// dx.doi.org/10.11646/phytotaxa.151.1.2

Cheek, M. \& M. Jebb, 2013f. Recircumscription of the Nepenthes alata group (Caryophyllales: Nepenthaceae), in the Philippines, with four new species. European Journal of Taxonomy, 69: 1-23. http://dx.doi.org/10.5852/ejt.2013.69

Cheek, M. \& M. Jebb, 2014. Expansion of the Nepenthes alata group (Nepenthaceae), Philippines, and descriptions of three new species. Blumea, 59: 144-154. http:// dx.doi.org/10.3767/000651914X685861

Cheek, M. \& M. Jebb, 2016a. A new section in Nepenthes (Nepenthaceae) and a new species from Sulawesi. Blumea, 61: 59-62. http://dx.doi.org/10.3767/000651916X691510.

Cheek, M. \& M. Jebb, 2016b. Nepenthes, three new infrageneric names and lectotypifications. Planta Carnivora 37: 34-42.

Cheek, M. M. Jebb, B. Murphy, \& F. Mambor, 2018. Nepenthes section Insignes in Indonesia, with two new species. Blumea 62: 174-178. https://doi.org/10.3767/blumea.2018.62.03.03

Danser, B.H., 1928. The Nepenthaceae of the Netherlands Indies. Bulletin du Jardin Botanique de Buitenzorg III, 9: 249-438.

Gronemeyer, T., F. Coritico, A. Wistuba, D. Marwinski, T. Gieray, M. Micheler, F.S. Mey, \& V. Amoroso, 2014. Four new species of Nepenthes L. (Nepenthaceae) from the Central Mountains of Mindanao, Philippines. Plants, 3: 284 -303. https://dx.doi.org/10.3390/plants3020284

Gronemeyer, T., W. Suarez, H. Nuytemans, M. Calaramo, A. Wistuba, F.S. Mey \& V.B. Amoroso, 2016. Two new Nepenthes species from the Philippines and an emended description of Nepenthes ramos. Plants, 5: 23. https:// dx.doi.org/10.3390/plants5020023

Heinrich, V., S.P. McPherson, T. Gronemeyer, \& V.B. Amoroso, 2009. Nepenthes micramphora (Nepenthaceae), a new species of Nepenthes L. from southern Mindanao, Philippines. In: McPherson S. (ed.) Pitcher Plants of the Old World. Redfern Natural History Publications, Dorset, U.K. pp. 1314-1319.

IUCN, 2012. IUCN Red List Categories and Criteria: Version 3.1. Second edition. IUCN, Gland.

Lagunday, N.E., F.M. Acma, V.G. Cabana, N.M. Sabas \& V.B. Amoroso, 2017. Two new Nepenthes species from the unexplored mountains of central Mindanao, Philippines. Philippine Journal of Science, 146: 159-165. 
Pelser, P.B., J.F. Barcelona \& D.L. Nickrent (ed.), 2011 onwards. Co's Digital Flora of the Philippines. www.philippineplants.org. (accessed 4 Mar 2019).

Sohmer, S.H. \& A.P. Davis, 2007. The genus Psychotria (Rubiaceae) in the Philippine Archipelago. Sida, 27: 1-247. 